\title{
Mapeamento dos Usos do Solo na Área de Proteção Permanente do Rio Vermelho (MT) e seus Reflexos sobre a Qualidade da Águai
}

\author{
Mapping of Land Use in the Permanent Protection Area of the Vermelho River (MT) \\ and its Effects on Water Quality
}

\author{
Mapeo de los Usos del suelo en el Área de Protección Permanente del Río Rojo \\ (MT) y sus Reflejos sobre la Calidad del Agua
}

\author{
André Valuz Souza ${ }^{1}$ \\ Simoni Loverde-Oliveira ${ }^{2}$ \\ Gustavo Benedito Medeiros Alves ${ }^{3}$
}

\begin{abstract}
RESUMO: O objetivo deste estudo foi mapear os usos do solo na Área de Proteção Permanente do Rio Vermelho e analisar seus efeitos sobre a qualidade da água no perímetro urbano de

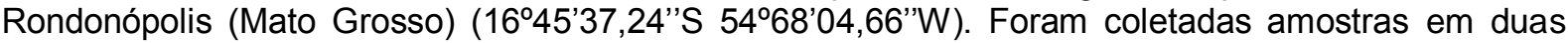
estações, com periodicidade trimestral no período seco e chuvoso de 2014. As análises da água seguiram os métodos padrões e para quantificar e classificar os diferentes usos do solo foram utilizadas imagens do programa Google EarthPro. Entre os usos do solo na APP registrou-se a ocorrência de mata ciliar em $74 \%$ da área (365 hectares) e $26 \%$ da área total (125,7 hectares) já foi desmatada para pastagem e mineração, entre outros usos. Entre as 22 variáveis indicadoras da qualidade da água, quatro apresentaram valores médios superiores aos limites da Resolução CONAMA 357/2005 para rio de classe II. Na época chuvosa houve maiores valores de cor, turbidez e fósforo total, e na seca houve aumento de coliformes fecais. A expansão das áreas urbanas associada aos usos praticados na região marginal em conflito com a Área de Preservação Permanente influenciou na qualidade física, química e biológica da água do rio Vermelho.
\end{abstract}

PALAVRAS-CHAVE: Geotecnologia. Vegetação ciliar. Rio Vermelho.

ABSTRACT: This study aimed to map the land uses in the Permanent Protection Area of the Vermelho River and to analyze their effects on the water quality in the urban perimeter of

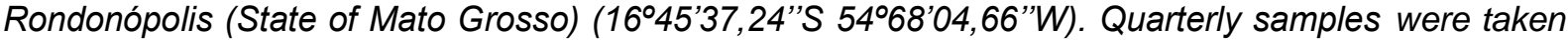
at two sites, in the dry and rainy seasons of 2014. Water analysis followed standard methods and in order to quantify and classify the different land uses, images from the Google EarthPro. Among the 22 variables indicating water quality, four presented mean values higher than the limits of CONAMA Resolution 357/2005 for class II rivers. In the rainy season, there were higher values of color, turbidity and total phosphorus, and in the dry season, there was an increase of fecal coliforms. Among the land

\footnotetext{
${ }^{1}$ Universidade Federal de Mato Grosso. Rodovia Rondonópolis-Guiratinga, Km 06, MT 270 - CEP 78735-901, Rondonópolis MT. andrevaluz@gmail.com.

${ }^{2}$ Universidade Federal de Mato Grosso. Rodovia Rondonópolis-Guiratinga, Km 06, MT 270 - CEP 78735-901, Rondonópolis MT. loverde@terra.com.br.

${ }^{3}$ Universidade Federal de Mato Grosso. Rodovia Rondonópolis-Guiratinga, Km 06, MT 270 - CEP 78735-901, Rondonópolis MT. gustavo.benedito@hotmail.com.
} 
uses in riparian vegetation, stand out the occurrence of riparian forest in $74 \%$ of the area (365 ha) and $26 \%$ of the total area (125.7 ha) has already been deforested for grazing, mining, among other uses. The expansion of urban areas associated with the practices on the banks in conflict with the APP directly influenced the physical, chemical and biological quality of the Vermelho River water.

KEYWORDS: Geotechnology. Riparian vegetation. Vermelho River.

RESUMEN: El objetivo del estudio fue mapear, usos del suelo en el Área de Protección Permanente del río Vermelho y analizar sus efectos sobre la calidad del agua en el perímetro urbano de Rondonópolis (Mato Grosso) (16\%45'37,24" S 5468'04,66"W). Se recogieron muestras en dos estaciones, con frecuencia trimestral en el período seco y lluvioso de 2014. Los análisis del agua se basaron en métodos estándar, para cuantificar y clasificar los diferentes usos del suelo se utilizaron imágenes del programa Google EarthPro. Entre los usos del suelo en la APP se verificó la prevalencia de vegetación ribereña en el $74 \%$ del área (365 ha) y el 26\% restante del área total (125,7 ha) fue deforestada para pastoreo, minería, entre otros usos. De las 22 variables indicadoras de la calidad del agua, cuatro presentaron valores medios superiores a los límites de la Resolución CONAMA 357/2005 para ríos de clase II. En la época lluviosa, mayores fueron los valores de color; turbidez y fósforo total, y en la época seca hubo incremento de los coliformes fecales. La expansión de las áreas urbanas asociadas con las actividades practicadas en la región marginal en conflicto con el Área de Preservación Permanente incidió en la calidad física, química y biológica del agua del río Vermelho.

PALABRAS CLAVES: Geotecnología. Vegetación ribereña. Río Vermelho.

\section{INTRODUÇÂO}

O uso e manejo inadequado da terra e a falta de ações conservacionistas implicam em perdas significativas de solo, matéria orgânica, nutrientes e biodiversidade, em especial a água, prejudicando o equilíbrio dos sistemas hídricos em bacias hidrográficas (VAEZA et al., 2010). Os usos da terra vêm sendo alterados com o crescimento populacional e fatores como poluição doméstica, altas taxas de consumo e escoamento superficial de água, além do desrespeito em áreas urbanizadas das Áreas de Proteção Permanente (APPs) ameaçam fortemente a disponibilidade e a qualidade da água (LIMA, 2013).

As atividades humanas que acontecem marginais a um rio influenciam nos aspectos da qualidade da água e podem restringir os possíveis usos do recurso hídrico. Assim, a análise do uso e ocupação do solo destaca-se como um fator primordial na avaliação ambiental, que não pode ser realizada apenas do ponto de vista físico, uma vez que deve ser entendido de forma integrada considerando-se a relação existente entre a degradação natural e as formas de uso e ocupação pela sociedade (ROMÃO; SOUZA, 2011).

O uso da geotecnologia é um elemento essencial para determinar a repartição geográfica do uso e da ocupação da terra, e a partir daí estabelecer quais são os reflexos desse uso sobre a qualidade da água. Nesse sentido, Rosa (2003) destaca que o uso da geotecnologia permite fazer uma análise integrada do ambiente de forma a entender como 
questões relacionadas às alterações ambientais se comportam no espaço e nos recursos hídricos.

Nos últimos anos, segundo Soares et al. (2011), as geotecnologias têm sido amplamente utilizadas no mapeamento e no monitoramento dos recursos naturais terrestres, se destacando como uma das alternativas mais viáveis e ágeis. Prova disso é a utilização de geotecnologias para o mapeamento automático de APPs (OLIVEIRA-FILHO; DUTRA; CERUTI, 2012; SANTOS; HERNANDEZ, 2013; SANTOS et al., 2014) e para o uso combinado desta ferramenta na analise da qualidade da água fluvial (ALVES; SANTOS, 2015; LIMA et al., 2015; SANTOS; ALVES, 2014; SOUZA, 2015).

Diante do fato que os usos da terra tem se intensificado e diversificado rapidamente, especialmente em áreas urbanas, causando impactos na biodiversidade florestal e nos sistemas fluviais, esse trabalho teve o objetivo de mapear os usos do solo na Área de Proteção Permanente do Rio Vermelho e analisar quais são os efeitos dos usos da terra sobre a qualidade da água no período seco e chuvoso.

\section{MATERIAL E MÉTODOS - ÁREA DE ESTUDO}

O município de Rondonópolis está localizado na porção sudeste do Estado de Mato Grosso ocupando uma área de 4.179 quilômetros quadrados, com uma população aproximada de 211.718 pessoas (IBGE, 2015). O município de Rondonópolis, a partir da década de 1970, apresentou progressivo crescimento populacional, sendo que tal condição não foi acompanhada pela determinação dos tipos de ocupação e manejo do solo. Desta forma, a localização do município no entroncamento de importantes rodovias de escoamento da safra de soja e algodão (BR 364 e 163), aliados a outros fatores sociais e econômicos fizeram com que ao longo do tempo o processo de colonização se tornasse intenso, promovendo Rondonópolis à segunda maior economia de Mato Grosso e à terceira em população (IBGE, 2015).

O clima regional é quente e úmido (médias anuais entre 22 a $26^{\circ} \mathrm{C}$ ), equivalente ao clima tropical (AW), com duas estações bem marcadas, uma seca e outra chuvosa (ALVARES et al., 2014), com pluviosidade média na bacia do rio Vermelho oscilando entre 1.400 a 2.000 milímetros (MATO GROSSO, 2011).

Neste estudo foi considerada a área de APP do Rio Vermelho (Bacia do rio Vermelho/São Lourenço) localizada no perímetro urbano de Rondonópolis (1645'37,24"S $\left.54^{\circ} 68^{\prime} 04,66^{\prime} \mathrm{W}\right)$, sendo que esta bacia tem uma extensão de 486,7 hectares.

Foram selecionadas duas estações no perímetro urbano para coleta de água no rio Vermelho (Figura 1), a primeira estação localiza-se próximo a Ponte da BR-364 (16²8'46,4"S 5439'6,4”W), onde a vegetação marginal é bastante degradada com reduzida 
Área de Proteção Permanente, visto que está inserida em área amplamente urbanizada. A segunda estação fica próxima à foz do Córrego Coronel Osvaldo (16²9'40,2"S $54^{\circ} 40^{\prime} 52,9^{\prime \prime} \mathrm{W}$ ), afluente do Rio Vermelho pela margem direita. A montante deste ponto de coleta (cerca de 1.300 metros) localiza-se a Estação de Tratamento de Esgoto de Rondonópolis, e também nas proximidades há cultivo de eucalipto e chácaras de veraneio, com vegetação ciliar bem conservada.

Figura 1 - Localização do perímetro urbano de Rondonópolis, assinaladas as estações de coleta da água
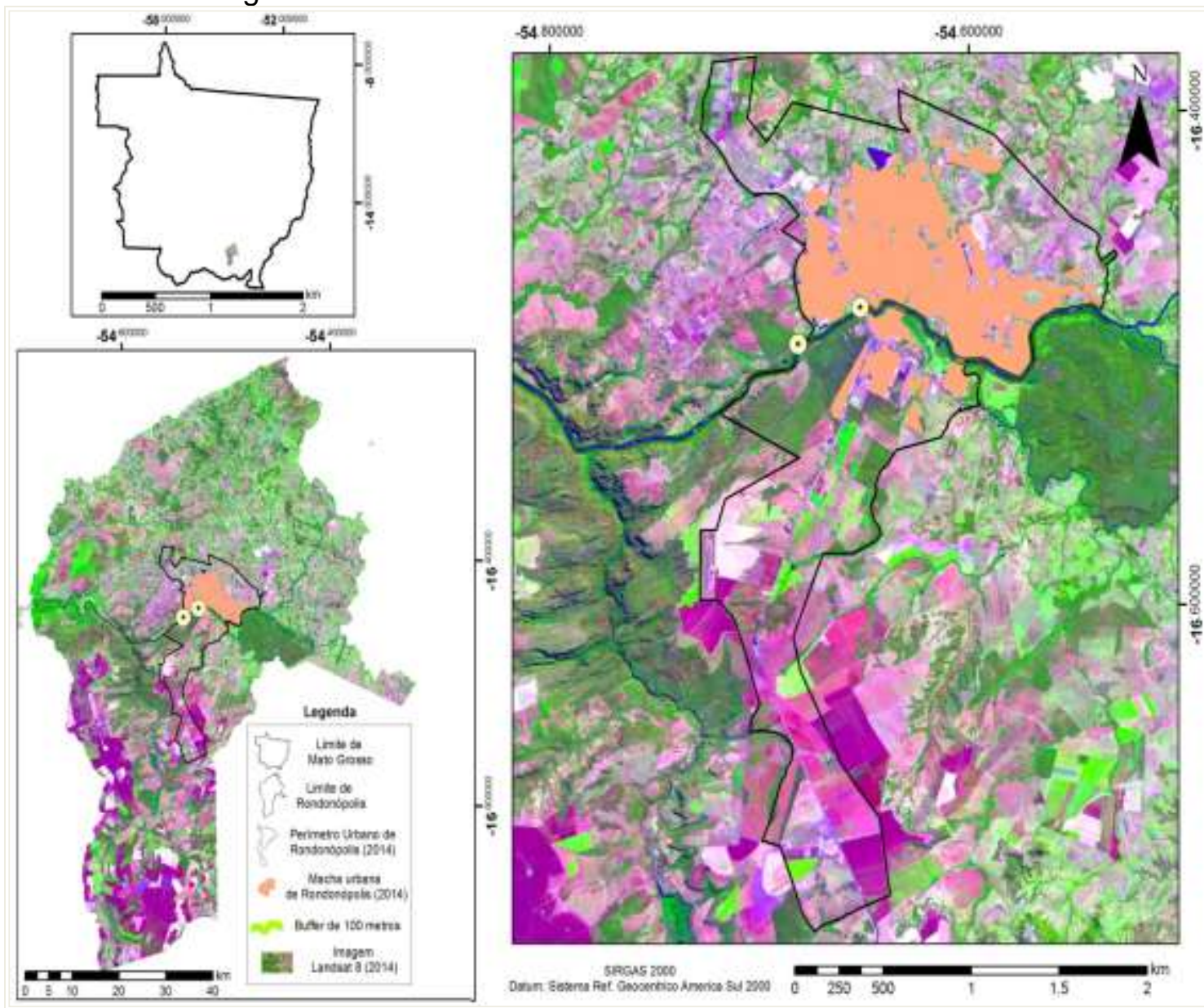

Fonte: Souza, 2015.

\section{METODOLOGIA}

Os dados limnológicos (22 variáveis) do Rio Vermelho foram coletados em 2014 com periodicidade trimestral. Os procedimentos metodológicos de análise da água descritos no Quadro 1 seguiram os padrões estabelecidos pela Standard Methods (APHA, 2005) e CETESB (BRANDÃO et al., 2011), que descrevem detalhadamente as técnicas utilizadas para cada método. As análises foram realizadas no Laboratório de Química do Departamento de Engenharia Sanitária e Ambiental (UFMT). 
Quadro 1 - Metodologias utilizadas para as análises físico-químicas e microbiológicas da água do Rio Vermelho, conforme o Standard Methods (APHA, 2005) e CETESB (2011)

\begin{tabular}{|c|c|}
\hline Variável & Método \\
\hline Temperatura da água & Termômetro \\
\hline Condutividade elétrica & Sonda de condutivímetro \\
\hline Cor & Espectrofotométrico \\
\hline Turbidez & Aparelho turbidimetro \\
\hline $\mathrm{pH}$ & Sonda de pHmetro \\
\hline OD & Sonda do oxímetro \\
\hline DQO & Potenciômetro \\
\hline DBO & Espectrofotométrico (Método Ácido Ascórbico) \\
\hline Alcalinidade & Potenciométrico \\
\hline Dureza Total & Titulométrico (E.D.T.A) \\
\hline Nitrogênio total & Espectrofotométrico (Método Fenato) \\
\hline Nitrogênio amoniacal & Espectrofotométrico \\
\hline Nitrogênio nitrato & Espectrofotométrico \\
\hline Nitrogênio nitrito & Espectrofotométrico (Ácido fenoldissulfônico) \\
\hline Fósforo total & Espectrofotométrico (Método Ácido Ascórbico) \\
\hline Ortofosfato & Titulométrico Cromatografia de ions \\
\hline Cloreto & Espectrofotométrico (Cloreto de Bário) \\
\hline Sulfato & Potenciômetro \\
\hline Resíduo Total & Gravimétrico \\
\hline Resíduo não filtrável & Gravimétrico \\
\hline Coliformes totais e fecais & Colilert \\
\hline
\end{tabular}

Fonte: Souza (2015).

Os resultados foram comparados com os limites máximos estabelecidos pela Resolução n. 357 do CONAMA de 2005 (CONAMA, 2005) para rios de classe II, tendo em vista que os rios de Mato Grosso não possuem enquadramento. Esta Resolução estabelece 
que sejam enquadrados nesta classe os corpos d'água que não possuem nenhuma proposta oficial de enquadramento pelos órgãos competentes.

O conjunto de dados foi submetido à Análise de Componentes Principais (ACP) para identificação dos fatores responsáveis pela variação temporal da qualidade de água, sendo que os coeficientes dos eixos foram calculados pelos autovetores da matriz de correlação e o número de componentes foi determinado pelo critério de Kaiser-Guttman, que retém aqueles com autovalores maiores que 1,0 (JACKSON, 1993).

Apenas variáveis com "loadings" maior que 0,75 foram consideradas como formadoras dos eixos da ACP (HAIR et al., 2009). Nesta análise foram utilizados os escores dos eixos da ACP aceitos para a interpretação como variáveis explanatórias e os logaritmos das variáveis limnologicas como variantes descritoras. Visando verificar se havia diferença entre os períodos seco e chuvoso, foi utilizada uma Análise de Variância Multivariada Permutacional (PERMANOVA), ambos usando o pacote estatístico SYSTAT 10.2®.

Baseando-se no Código Florestal Brasileiro (BRASIL, 2012) e no Código Ambiental do Município de Rondonópolis (RONDONÓPOLIS, 2002) que estabelece a largura de 100 metros de APP para cursos hídricos de 50 a 200 metros, como é o caso do Rio Vermelho (largura média de 86 metros), foi delimitado um buffer de 100 metros de largura no entorno das margens deste rio pelo software ArcGis $10.2^{\circledR}$ para estabelecer a área da APP.

Com a utilização do Sistema de Informações Geográficas (SIG) foi delimitado e quantificado os diferentes usos e ocupação do solo na área de Preservação Permanente do Rio Vermelho. Após a etapa de delimitação foi gerado um banco de dados (SIG), com as imagens de Satélite do Google Earth Pro (15-03-2014) com resolução espacial de 2,5 metros. A região de APP foi mapeada através de uma classificação visual, estabelecidas as seguintes categorias de usos: pastagem, florestal, campestre, área urbanizada, corpo d'água continental e área de mineração, utilizando o manual técnico do Instituto Brasileiro de Geografia Estatística (IBGE, 2013).

Apoiando-se na abordagem de Moreira et al. (2011) e Lanznaster (2011) as imagens de alta resolução espacial foram capturadas pelo programa Google Earth para a criação de vetores shapefile com o objetivo de interpretar os diferentes tipos de usos da terra da APP do Rio Vermelho. Os vetores foram criados no sistema UTM com DATUM SIRGAS 2000. Para melhor caracterizar as classes de usos, foram feitas observações em campo para aferir dados e georeferenciar locais com distintos usos do solo. 


\section{RESULTADOS E DISCUSSÃO}

Considerando as variáveis que caracterizaram a água do Rio Vermelho é possível afirmar que em média a temperatura da água variou de $29,4{ }^{\circ} \mathrm{C}$ (estação 1) a $29,6{ }^{\circ} \mathrm{C}$ (estação 2); a condutividade elétrica variou em média de 61,65 $\mu \mathrm{S} / \mathrm{cm}$ (estação 1) a 54,2 $\mu \mathrm{S} / \mathrm{cm}$ (estação 2); e o potencial hidrogeniônico $(\mathrm{pH})$ variou em média de 7,05 (estações 1) até 7,25 (estação 2). A cor variou em média de 104,85 U.C. (estação 1) a 107,45 U.C. (estação 2); e a turbidez de 124,35 UNT (estação 1) a 151,35 UNT (estação 2).

Na Figura 2A são apresentadas as variações medias dos sólidos totais que oscilaram de 399,2 mg/L (estação 1) a 294,5 mg/L (estação 2), os sólidos não filtráveis que variaram em média de 90,55 (estação 1) a 14,75 mg/L (estação 2). A alcalinidade variou em média de 13,95 mg/L $\mathrm{CaCO}_{3}$ (estação 1) a 11,95 mg/L $\mathrm{CaCO}_{3}$ (estação 2). A demanda bioquímica de oxigênio (DBO) variou em média de $1,25 \mathrm{mg} / \mathrm{L}$ em ambas as estações. A demanda química de oxigênio (DQO) variou em média de $34 \mathrm{mg} / \mathrm{L}$ (estação 1) a 24,75 mg/L (estação 2) (Figura 2A).

O nitrogênio Kjedahl total variou em média de $1,15 \mathrm{mg} / \mathrm{L}$ (estação 2) a 0,90mg/L (estação 2), o nitrato variou em média de 0,3 mg/L (estação 1) a 0,18 mg/L (estação 2), o nitrito variou em média de $0,0085 \mathrm{mg} / \mathrm{L}$ (estação 1) a 0,0095 mg/L (estação 2), o nitrogênio amoniacal variou em média de $0,2285 \mathrm{mg} / \mathrm{L}$ (estação 1) até $0,2875 \mathrm{mg} / \mathrm{L}$ (estação 2). $\mathrm{O}$ ortofosfato variou em média de $0,355 \mathrm{mg} / \mathrm{L}$ (estação 1) a 0,21 mg/L (estação 2). O cloreto variou em média de 2,35 mg/L (estação 1) a 2,0 mg/L (estação 2) e quanto ao sulfato houve variação média de 5,9 mg/L (estação 1) até 5,5 mg/L (estação 2) (Figura 2B).

De maneira geral, a maioria das variáveis analisadas no Rio Vermelho esteve dentro dos limites estabelecidos pelo CONAMA 357/2005 (Tabela 1), exceto a turbidez, cor, fósforo total e coliforme fecal, as quais puderam ser relacionadas com os usos do solo.

Desta forma, quando analisadas espacial e temporalmente somente as variáveis cujos valores estiveram acima dos parâmetros do CONAMA, verificou-se que a turbidez na estação 1 (área urbana) variou de 19,7 a 229 NTU, e na estação 2 (perímetro urbano) variou de 22,7 a 280 NTU. Esta variável no período chuvoso esteve acima do limite do CONAMA 357/2005, mas no período seco apresentou valores aceitáveis. A cor na estação 1 variou de 59,1 a 150,6 U.C. e na estação 2 variou de 51,3 a 163,6 U.C. No período chuvoso a cor também esteve acima do limite do CONAMA 375/2005, e no período seco apresentou valores dentro do limite máximo, corroborando para esse resultado, os estudos de Sette, Tarifa e Gripp (2002), Loverde-Oliveira; Silva (2010), Araújo (2012), Souza e LoverdeOliveira (2014) que também registraram valores de cor e turbidez acima do limites de tolerâncias para rio de classe II, com valores mais elevados em episódios de chuvas mais intensas. 
Figuras 2 A e 2 B - Variação espacial dos valores médios dos parâmetros limnológicos nas estações 1 e 2 amostradas no Rio Vermelho

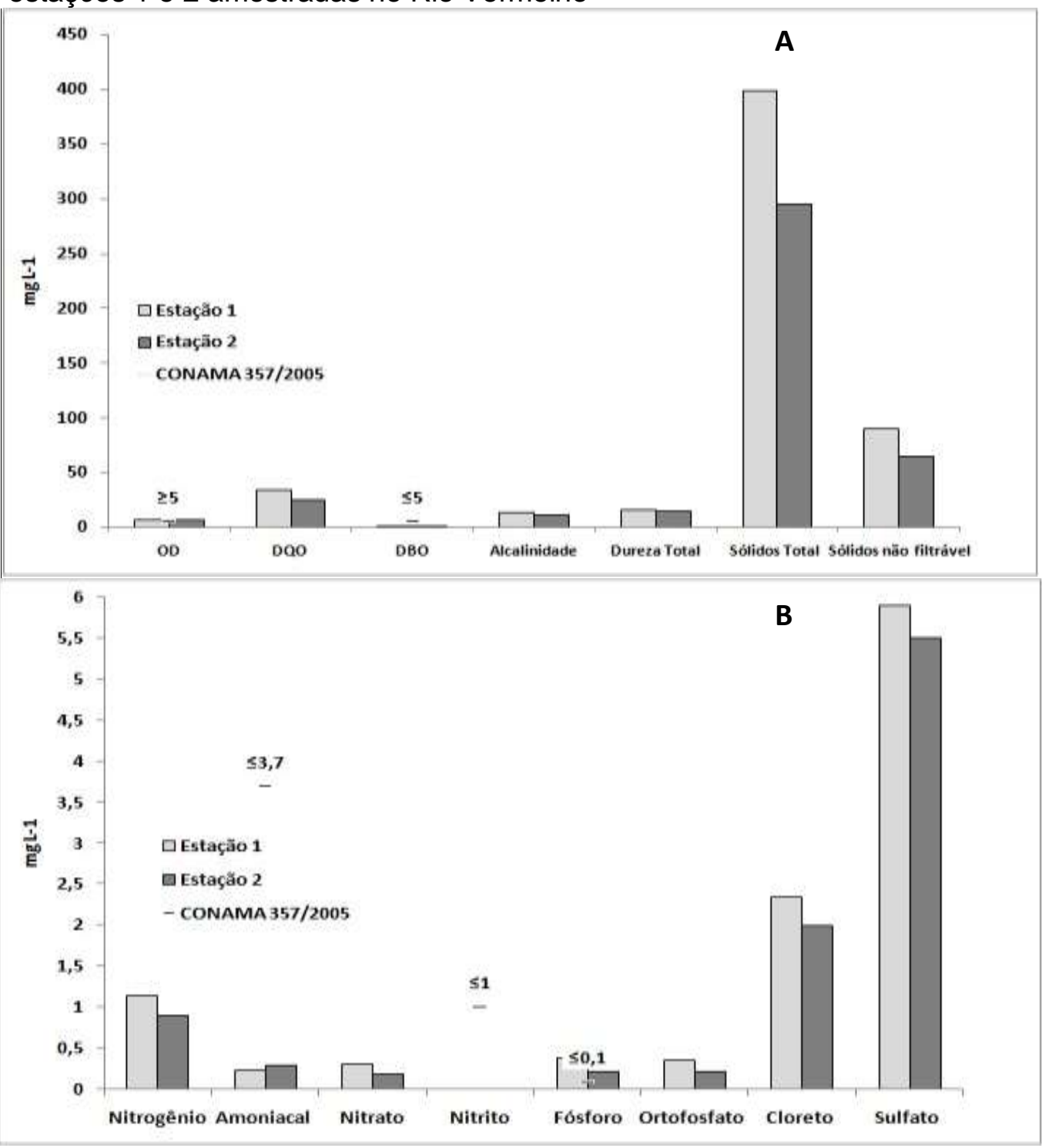

Fonte: o próprio autor.

Este padrão com altos valores de cor e turbidez no período chuvoso documentado em diversos rios brasileiros é atribuído à presença de maior quantidade de sólidos em suspensão (CETESB, 2006). A baixa cobertura de vegetação nativa proporciona o carreamento de grandes quantidades de solo, matéria orgânica e insumos agrícolas para o leito dos cursos d'água no período chuvoso, contribuindo significativamente com o aumento da concentração de sólidos e nutrientes na água dos mananciais (DONADIO; GALBIATTI; PAULA, 2005).

O fósforo total na estação 1 variou de 0,13 a $0,63 \mathrm{mg} \cdot \mathrm{L}^{-1}$, e na estação 2 variou de 0,12 a $0,31 \mathrm{mg} \cdot \mathrm{L}^{-1}$. As concentrações do fósforo total em todas as estações e épocas estiveram acima do limite do CONAMA 357/2005 (CONAMA, 2005). No estudo de Araújo 
(2012), as concentrações de fósforo total estiveram acima dos limites permitidos durante todos os meses monitorados, sendo que o lançamento de efluentes domésticos e industriais oriundos da área urbana foi apontado por terem contribuído para o aumento dessas concentrações. Segundo Lima (2013), Souza e Gastaldini (2014), o aporte de fósforo e seus componentes nos recursos hídricos têm como principal agente o uso urbano, seguido pelo uso agrícola do solo.

Tabela 1 - Intervalo de variação limnológica do Rio Vermelho, por estação de amostragem. Valores estabelecidos pelo CONAMA 357/2005. Em negrito as variáveis acima do limite

\begin{tabular}{|c|c|c|c|}
\hline Variável & $\begin{array}{l}\text { CONAMA } \\
357 / 2005\end{array}$ & $\begin{array}{l}\text { Estação } 1 \\
\text { Min - Max }\end{array}$ & $\begin{array}{l}\text { Estação } 2 \\
\text { Min - Max }\end{array}$ \\
\hline Temperatura da água $\left({ }^{\circ} \mathrm{C}\right)$ & - & $27,9-30,9$ & $28,1-31,1$ \\
\hline Condutividade elétrica $\left(\mu \mathrm{S} . \mathrm{cm}^{-1}\right)$ & - & $60,1-63,2$ & $-52,7-55,7$ \\
\hline $\mathrm{pH}$ & 6,0 a 9,0 & $6,8-7,3$ & $7,1-7,4$ \\
\hline $\mathrm{OD}\left(\mathrm{mg} \cdot \mathrm{L}^{-1}\right)$ & $\geq 5,0$ & $6,2-6,5$ & $6,2-7,1$ \\
\hline $\mathrm{DQO}\left(\mathrm{mg}^{\left.-\mathrm{L}^{-1}\right)}\right.$ & $<5,0$ & $33,0-35,0$ & $22,5-27,0$ \\
\hline $\mathrm{DBO}\left(\mathrm{mg} \cdot \mathrm{L}^{-1}\right)$ & - & $1,0-1,5$ & $1,0-1,5$ \\
\hline Alcalinidade $\left(\mathrm{mg}^{-1} \mathrm{~L}^{-1} \mathrm{CaCO}_{3}\right)$ & - & $13,4-14,5$ & $10,3-13,6$ \\
\hline Dureza Total $\left(\mathrm{mg} \mathrm{L}^{-1} \mathrm{CaCO}_{3}\right)$ & - & $16,1-16,8$ & $14,3-15,2$ \\
\hline Cor (U.C.) & $\leq 75$ & $59,1-150,6$ & $51,3-\mathbf{1 6 3 , 6}$ \\
\hline Turbidez (NTU) & $\leq 100$ & $19,7-\mathbf{2 2 9 , 0}$ & $22,7-280,0$ \\
\hline Sólidos Total $\left(\mathrm{mg} \mathrm{L}^{-1}\right)$ & & $398,7-399,7$ & $311,5-277,5$ \\
\hline Sólidos não filtrável $\left(\mathrm{mg} \mathrm{L}^{-1}\right)$ & & $44,9-136,2$ & $37,0-93,5$ \\
\hline Nitrogênio Total $\left(\mathrm{mg} \mathrm{L}^{-1}\right)$ & - & $0,9-1,4$ & $0,8-1,0$ \\
\hline Amoniacal $\left(\mathrm{mg}^{\mathrm{L}} \mathrm{L}^{-1}\right)$ & $\leq 3,7$ & $0,112-0,345$ & $0,350-0,225$ \\
\hline Nitrato $\left(\mathrm{mg} \cdot \mathrm{L}^{-1}\right)$ & $\leq 10$ & $0,09-0,51$ & $0,07-0,29$ \\
\hline Nitrito $\left(m g . L^{-1}\right)$ & $\leq 1$ & $0,005-0,012$ & $0,013-0,006$ \\
\hline Fósforo Total $\left(\mathrm{mg}^{-\mathrm{L}^{-1}}\right)$ & $\leq 0,10$ & $0,13-0,63$ & $0,12-0,31$ \\
\hline Ortofosfato $\left(\mathrm{mg} \cdot \mathrm{L}^{-1}\right)$ & - & $0,02-0,69$ & $0,02-0,40$ \\
\hline Cloreto $\left(\mathrm{mg} \cdot \mathrm{L}^{-1}\right)$ & $\leq 250$ & $1,5-3,2$ & $1,1-2,9$ \\
\hline Sulfato $\left(m g \cdot \mathrm{L}^{-1}\right)$ & $\leq 250$ & $5,0-6,8$ & $4,5-6,5$ \\
\hline Coliformes totais (NMP. $100 \mathrm{ml}^{-1}$ ) & - & $24196-24196$ & $24196-24196$ \\
\hline Escherichia coli (NMP.100ml ${ }^{-1}$ ) & $\leq 1000$ & $1760-2248$ & $15531-8737$ \\
\hline
\end{tabular}

Fonte: Souza (2015).

O coliforme fecal (Escherichia coli) na estação 1 variou de 1760,5 a 2248,5 NMP.100 $\mathrm{mL}^{-1}$, e na estação 2 variou de 15531,5 a $8737,5 \mathrm{NMP} .100 \mathrm{~mL}^{-1}$. Esta variável esteve acima do limite do CONAMA 357/2005 nos períodos seco e chuvoso, com maiores valores na época seca. Num estudo recente Souza e Loverde-Oliveira (2014) obtiveram na bacia do Rio Vermelho valores médios acima do limite para rios de classe II. Segundo Fava (2012) os níveis mais altos de $E$. coli são normalmente encontrados nos períodos de estiagem nos quais sua concentração é maior que no período chuvoso. Conforme estes autores, a determinação da concentração dos coliformes assume importância também como parâmetro indicador da possibilidade de existência de microrganismos patogênicos, responsáveis pela transmissão de doenças de veiculação hídrica.

Alguns estudos têm documentado importantes mudanças biológicas ao longo do gradiente urbano-rural com prejuízos na qualidade da água (GROFFMAM; GRAWFORD, 
2003) e a degradação dos sistemas fluviais (HELMS; FEMINELLA; PAN, 2005; JAYAWARDANA et al., 2017), além disso, sabe-se que os usos urbanos tem influenciado na estrutura e diversidade de espécies da vegetação ciliar (BURTON; SAMULSON, 2008).

Para compreender as relações entre as variáveis limnológicas e os períodos climáticos foi realizada uma ACP (Análise dos Componentes Principais). Foram obtidos quatro fatores com autovalor maior que 1,0 (VF1, VF2, VF3 e VF4) que, reunidos, explicam $93,8 \%$ da variância total dos dados limnológicos.

Os dois primeiros eixos explicaram $69,55 \%$ dos dados sendo que o fator VF1 explicou $37,7 \%$ da variância total, assim as variáveis turbidez, amônia, nitrato e coliformes fecais contribuem para este fator. O VF2 explica $31,8 \%$ da variação, sendo cor, fósforo, ortofosfato e sólidos totais as principais variáveis deste fator. O fator VF3 e VF4 não tiveram escores maiores que 0,75. A PERMANOVA realizada com os dois primeiros eixos da PCA indicou variação significativamente diferente para as variáveis limnológicas entre os períodos seco e chuvoso ( $F=4,97 ; p=0,001$ ) (Figura 3). Assim, demonstraram de forma bem nítida que as variações na cor, turbidez, fósforo total estão associadas ao período chuvoso e sólidos totais, amônia e Escherichia coli com o período seco.

Figura 3 - Diagrama da Análise do Componente Principal das variáveis limnológicas do Rio Vermelho nos período seco e chuvoso

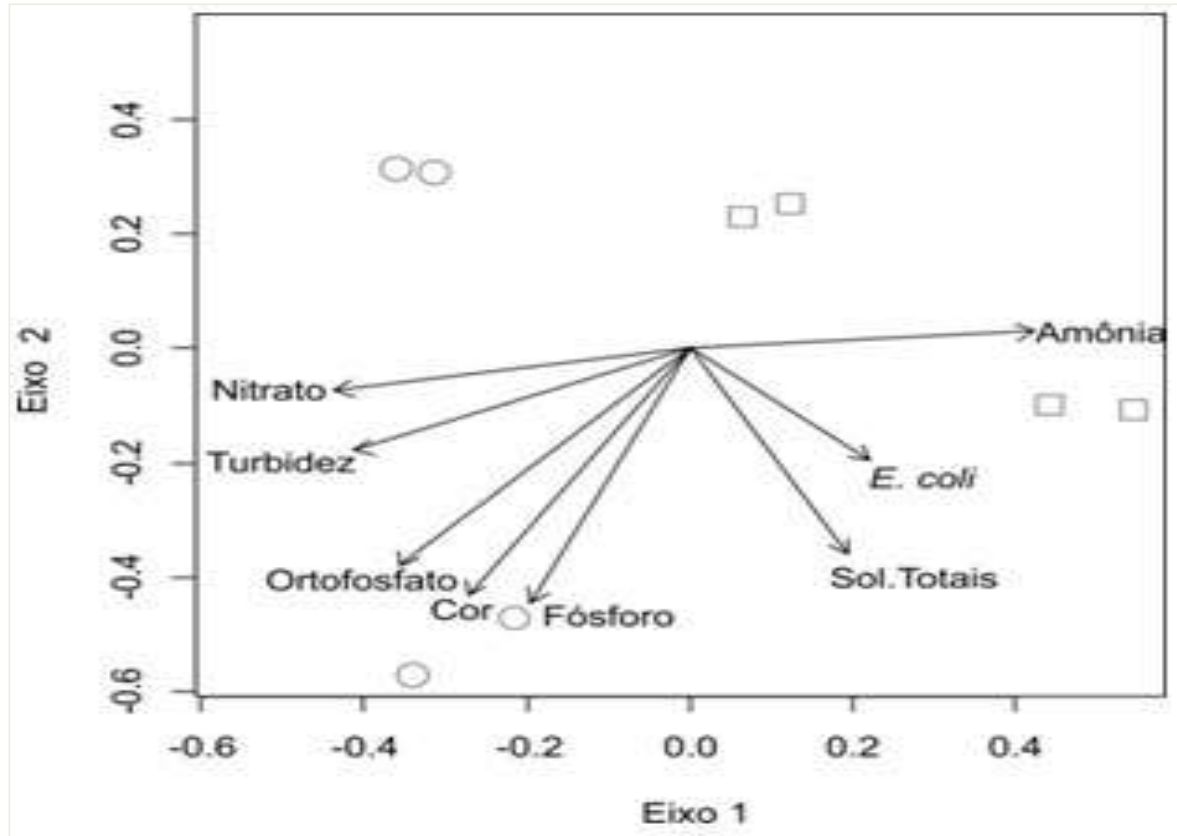

Fonte: Souza (2015).

De maneira geral, entre as classes de usos do solo, foi verificado que a mata ciliar remanescente na APP do Rio Vermelho permanece ocupando 74\% (365 hectares) e 26\% (125,7 hectares) da área total. Já foi desmatada e está atualmente sendo ocupada para outras atividades. Dessa área total desmatada 16\% (77,6 hectares) é usada para pastagem, 
3,5\% (16,8 hectares) é usada como recuperação da vegetação (campestre), 3,3\% (15,8 hectares) são áreas urbanizadas, 1,0\% (4,9 hectares) é usada na mineração, 0,3\% (1,3 hectares) é área descoberta, 0,2\% (0,8 hectares) representa corpos d'água (córregos, represas) e 1,70\% (8,5 hectares) teve uso não identificado (Figura 4A e 4B).

Figura 4A - Mapa do uso e ocupação do solo da APP do rio Vermelho no perímetro urbano de Rondonópolis; assinaladas as estações de coleta de água. A - classe Florestal, B e C - classe Área Urbanizada

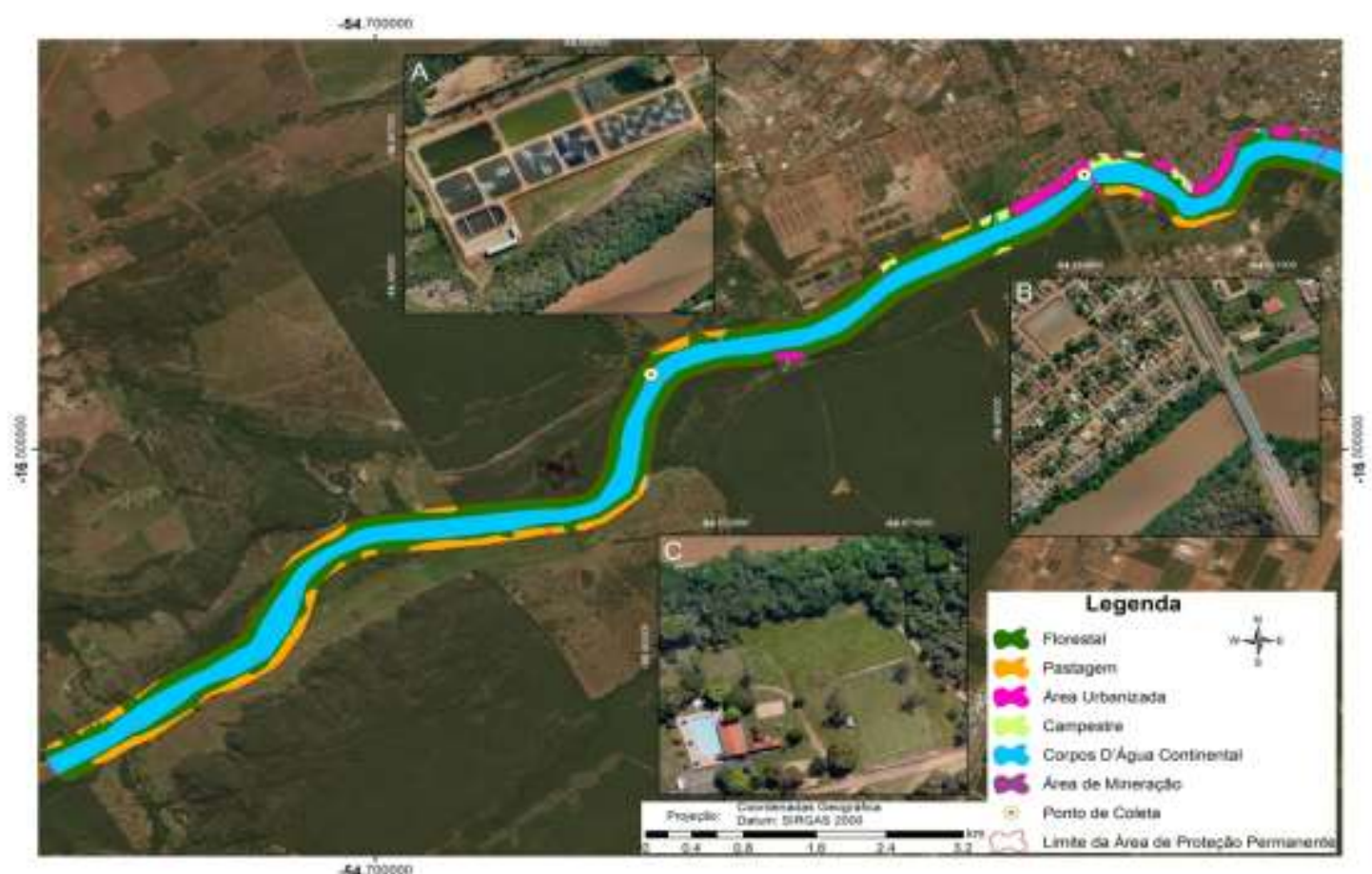

Fonte: o próprio autor.

Entre os usos registrados na margem do Rio Vermelho, há alguns fatores intervenientes na qualidade da água, entre eles a retirada da mata ciliar dando lugar à atividade agropecuária e urbanização. Estes usos, segundo Bailly et al. (2012), geram problemas drásticos e aceleram os processos degeneradores do ambiente aquático. $\mathrm{A}$ retirada da cobertura vegetal, como já é sabido, aumenta a probabilidade de erosão dos solos, uma vez que a perda da camada superior do solo e o aumento do escoamento superficial conferem aos corpos d'água um acréscimo da concentração de sólidos suspensos, micropoluentes inorgânicos e orgânicos, além de outros compostos presentes no solo e nas rochas (OLIVEIRA-FILHO; DUTRA; CERUTI, 2012).

A APP do Rio Vermelho no perímetro urbano encontra-se bem conservada, devido à mata ciliar da margem esquerda desse rio ainda atender o pressuposto do Código Florestal Brasileiro (BRASIL, 2012) onde há poucos usos antrópicos. Já na margem direita desse rio os usos não vêm cumprindo a legislação vigente. Um estudo desenvolvido por Coutinho et al. (2013) na APP bacia do Rio da Prata (ES), entre outras obras similares (BAILLY et al., 
2012; SANTOS; ALVES, 2014; SOARES et al., 2011), indica a presença de atividades antrópicas nas mesmas. Consequentemente os usos estão em desacordo com a legislação.

Figura 4B - Mapa do uso e ocupação do solo da APP do rio Vermelho no perímetro urbano de Rondonópolis. D - classe Mineração, E- classe Pastagem e Florestal, F- classe Campestre

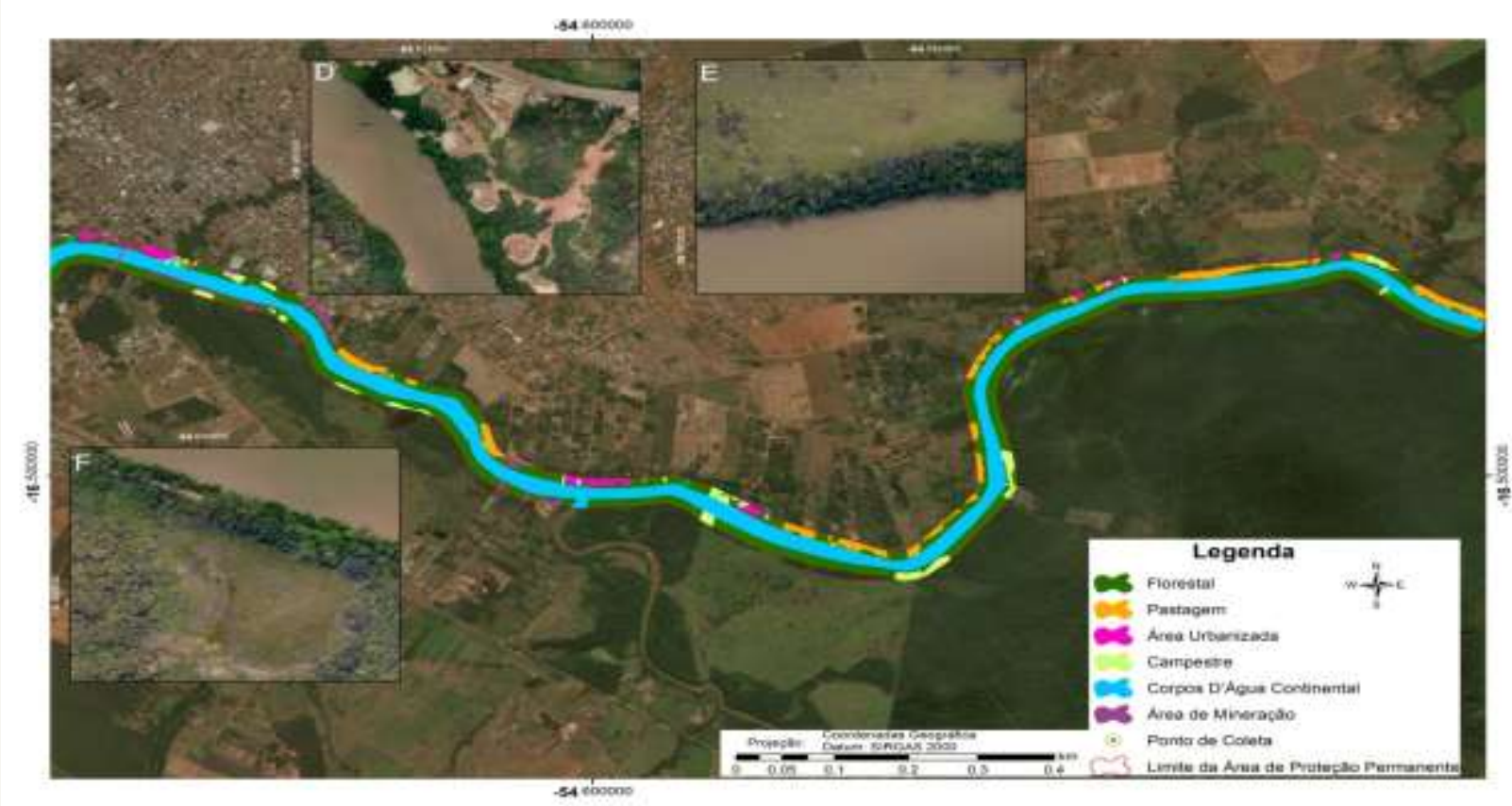

Fonte: o próprio autor.

Os usos e ocupação do solo na APP na área urbana de Rondonópolis (Figuras 3A e 3B) evidenciaram a degradação das matas ciliares, e esse processo vem comprometendo a proteção ambiental e alterando a qualidade da água, tanto no período chuvoso quanto no período seco. Nesse contexto, Davide et al. (2000) comentam que as zonas ripárias tem papel de barreira física entre ambiente terrestre e aquático, possuindo a função de filtro da água de escoamento superficial retendo até $80 \%$ do fósforo e $89 \%$ do nitrogênio. Este resultado é corroborado por Pontes, Marques e Marques (2012) que detectaram que em áreas com vegetação ciliar mais íntegra há menor concentração de poluentes.

As ocupações irregulares nas APP apresentam reflexos sobre a qualidade da água, uma vez que usos para pastagem, área urbana, estrada, mineração e solo exposto, entre outros, geraram uma condição ambiental distinta e demonstrada pelas alterações das variáveis limnológicas que em determinadas épocas e locais já se mostram acima dos limites aceitáveis para rios da classe II.

É fato que a má conservação do solo e a expansão das áreas urbanas associadas ao uso em conflito com as APP influenciam diretamente na qualidade física e biológica da água do rio Vermelho especialmente no perímetro urbano. Assim, o monitoramento das águas é de fundamental importância para fins de se constituir um banco de dados e ao mesmo 
tempo identifique os fatores passíveis de afetar a disponibilidade hídrica que, sem dúvida, constitui um fator limitante para o abastecimento local, considerando que, na cidade de Rondonópolis $55 \%$ da água utilizada para abastecimento humano é captada desse rio (TONIN, 2013) e que esse corpo d'água recebe influência tanto do processo de urbanização quanto dos usos praticados a montante na bacia.

\section{CONCLUSÃO}

As variáveis limnológicas do Rio Vermelho que estão acima dos limites máximos para corpos d'água de classe II estão relacionadas à ótica da água (cor e turbidez), ao estado trófico (fósforo total) e aos componentes biológicos (coliformes fecais).

As atividades referentes à exploração do solo para pecuária, urbano e áreas em recuperação têm ocasionado erosão e maior disponibilidade de sedimentos e consequentemente agindo negativamente sobre a oferta de luz na coluna d'água, principalmente no período chuvoso; o lançamento de efluentes por fontes diversas podem ser apontado como o responsável pelas elevadas quantidades de fósforo e coliformes fecais interferindo na trófia do ambiente. Nesse sentido, já é possível afirmar que alguns dos usos praticados na região marginal do Rio Vermelho e na sua bacia de drenagem têm afetado a qualidade da água.

Fica evidente, portanto, que a má conservação solo e a expansão das áreas urbanas associadas ao uso em conflito com as APP influenciam diretamente a qualidade física e biológica do Rio Vermelho no perímetro urbano. Tal condição demonstra claramente que as leis regulamentares têm sido desobedecidas e consequentemente há degradação em áreas que deveriam ser usadas exclusivamente com a finalidade de preservação.

\section{REFERÊNCIAS}

ALVARES, C. A.; STAPE, J. L.; SENTELHAS, P. C.; MORAES, G.; LEONARDO, J.; SPAROVEK, G. Koppen's climate classification map for Brazil. Meteorologische Zeitschrift, Berlin, v. 22, n. 6, p. 711-728, 2014.

ALVES, G. B. M.; SANTOS, J. W. M. C. Mapeamento da temperatura das águas superficiais do reservatório de Manso-MT com dados extraídos de imagens modis e coletas in loco. In: SIMPÓSIO BRASILEIRO DE SENSORIAMENTO REMOTO, 17, 2015, João Pessoa-PB. Anais ... João Pessoa: INPE, 2015. p. 7096 -7102.

APHA. American Public Health Association et al. (ed.). Standard methods for the examination of water and wastewater. $21 \mathrm{ed}$. Washington: American Water Works Association; Water Pollution Control Federation, 2005.

ARAÚJO, G. C. Padrões espaciais da qualidade da água na bacia do rio Cuiabá e rio São Lourenço - Mato Grosso. 2012. 94 f. Dissertação (Mestrado em Recursos Hídricos) Universidade Federal de Mato Grosso, Cuiabá. 
BAILLY, D.; FERNANDES, C. A.; SILVA, V. F. B.; KASHIWAQUI, E. A. L.; DAMÁSIO, J. F.; WOLF, M. F.; RODRIGUES, M. C. Diagnóstico ambiental e impactos sobre a vegetação ciliar da microbacia do córrego da Ponte, Área de Proteção Ambiental do rio Iguatemi, MS. Agronegócios e Meio Ambiente, Maringá, v. 5, n. 2, p. 409-427, 2012.

BRANDÃO, C. J.; BOTELHO, M. J. C.; SATO, M. I. Z.; LAMPARELL, M. C. (org.). Guia nacional de coleta e preservação de amostras: água, sedimento, comunidades aquáticas e efluentes líquidos. São Paulo: CETESB; Brasília: ANA, 2011.

BRASIL. Lei no 12.651, de 25 de maio de 2012. Código Florestal. Disponível em: <http: www.planalto.gov.br/ccivil_03/_ato2011-2014/2012/lei/l12651.htm.> Acesso em: 17 mar. 2015.

BURTON, M. L.; SAMULSON, L. J. Influence of urbanization on riparian forest diversity and struture in the Georgia Piedmont, US. Plant Ecology, Dordrecht, v. 195, n. 1, p. 99-115, 2008.

CETESB. Companhia Ambiental do Estado de São Paulo. Variáveis de qualidade das águas. 2006. Disponível em: <http://www.cetesb.sp.gov/agua/rios/variaves >. Acesso em: 28 abr. de 2014.

CONAMA. Conselho Nacional do Meio Ambiente. Resolução CONAMA n 357, de 17 de março de 2005. Classificação dos corpos de água e diretrizes ambientais para o seu enquadramento, bem como estabelece as condições e padrões de lançamento de efluentes. Disponível em: <http://www.mma.gov.br/port/conama/res/res05/>. Acesso em: 20 abr. 2014.

COUTINHO, L. M.; ZANETTI, S. S.; CECÍLIO, R. A.; GARCIA, G. O.; XAVIER, A. C. Usos da terra e Áreas de Preservação Permanente (APP) na bacia do rio da Prata, Castelo-ES. Floresta e Ambiente, Rio de Janeiro, v. 20, n. 4, p. 425-434, 2013.

DAVIDE, A. C.; FERRREIRA, R. A.; FARIA, J. M. R.; BOTELHO, S. A. Restauração de matas ciliares. Informe Agropecuário, Belo Horizonte, v. 21, n. 207, p. 65-74, 2000.

DONADIO, N. M. M.; GALBIATTI, J. A.; PAULA, R. C. de. Qualidade da água de nascentes com diferentes usos do solo na bacia hidrográfica do Córrego Rico. São Paulo, Brasil.

Engenharia Agrícola, Jaboticabal, v. 25, n. 1, p. 115-125, 2005.

FAVA, R. A. C. Caracterização quali-quantitativa da bacia hidrográfica do rio dos Bugres-MT visando o planejamento e gestão de recursos hídricos. 2012. $142 \mathrm{f}$. Dissertação (Mestrado em Recursos Hídricos) - Universidade Federal de Mato Grosso, Cuiabá.

GROFFAM, P. M.; GRAWFORD, M. K. Denitrification potential in urban riparian zones. Journal of Environmental Quality, Madison, v. 32, n. 3, p. 1144-1149, 2003.

HAIR, J. F. et al. Análise multivariada de dados. 6 ed. Porto Alegre: Bookman, 2009.

HELMS, B. S.; FEMINELLA, J. W.; PAN, S. Detection of biotic responses to urbanization using fish assemblages from small streams of weatern Georgia, USA. Urban Ecosystem, Duluth, v. 8, p. 39-59, 2005.

IBGE. Estados: Mato Grosso. 2015. Disponível em:

<http://www.ibge.gov.br/estadosat/perfil.php?sigla=mt\#>. Acesso em: 15 mar. 2015.

Manual técnico de uso da terra. 3 ed. Rio de Janeiro, 2013.

JACKSON, D. A. Stopping rules in principal components analysis: a comparison of heuristical and statistical approaches. Ecology, Brooklyn, v. 74, p. 2204-2214, 1993.

JAYAWARDANA, J. M. C. K.; GUNAWARDA, W. D. T. M.; UDAYAKUMARA, E. P. N.; WESTBROOKE, M. Land use impacts on river health of Uma Oya, Sri Lanka: implications of spacial scales. Environmental Monitoring and Assessment, Dordrecht, v. 189, n. 4, p. 192, 2017. 
LANZNASTER, M. Utilização de imagens do Google Earth para definir o uso do solo de propriedades rurais. 2011. Monografia (Especialização em Georreferenciamento de Imóveis) - Departamento de Engenharia Florestal. Universidade Regional de Blumenau. Disponível em: <http://www.bc.furb.br/docs/mo/2011/348767_1_1.pdf>. Acesso em: 12 de maio de 2014.

LIMA, C. R. N. Variabilidade espacial de parâmetros de qualidade de água nas bacias do rio Cuiabá e São Lourenço. 2013. 86 f. Dissertação (Mestrado em Engenharia Civil e Ambiental) - Universidade Federal de Mato Grosso. Cuiabá.

., ZEILHOFER, P.; DORES, E. F. G. C.; CRUZ, I. Variabilidade espacial da qualidade de água em escala de bacias - Rio Cuiabá e São Lourenço, Mato Grosso. Revista

Brasileira de Recursos Hídricos, Porto Alegre, v. 20, p. 169-178, 2015.

LOVERDE-OLIVEIRA, S. M.; SILVA, M. C. Limnologia dos ecossistemas fluviais do perímetro urbano de Rondonópolis, Mato Grosso. In: SANTOS, J. W. M. C. (org.). Produção do espaço e transformações socioambientais das paisagens do Mato Grosso. Cuiabá: UFMT, 2010. p. 123-144.

MATO GROSSO. Secretaria de Estado de Planejamento e Coordenação Geral. Atlas de Mato Grosso. Cuiabá: Entrelinhas, 2011.

MOREIRA, M.; ADAMI, M.; RUDORFF, B. F. T.; BERNARDES, T. Uso de imagens do Google Earth capturadas através do software stitchmap e do TM Ladsat-5 para mapeamento de lavouras cafeeiras - nova abordagem metodológica. In: SIMPÓSIO BRASILEIRO DE SENSORIAMENTO REMOTO, 15, 2011, Curitiba. Anais. Curitiba: INPE, 2011, p. 0481 0488. Disponível em: <https://www.dsr.inpe.br/sbsr2011/files/p0616.pdf>. Acesso em: 10 maio 2014.

OLIVEIRA-FILHO, P. C. O.; DUTRA, A. M.; CERUTI, F. C. Qualidade das águas superficiais e o uso da terra: estudo de caso pontual em bacia hidrográfica do oeste do Paraná. Floresta e Ambiente, Rio de Janeiro, v. 19, n. 1, p. 32-43, 2012.

PONTES, P. P.; MARQUES, A. R.; MARQUES, G. F. Efeito do uso e ocupação do solo na qualidade da água na micro-bacia do Córrego Banguelo - Contagem. Ambiente e Água, Taubaté, v. 7, n. 3, p. 183-194, 2012.

ROMÃO, A. C. B. C.; SOUZA, M. L. Análise do uso e ocupação do solo na bacia do Ribeirão São Tomé, Noroeste do Paraná - PR (1985 e 2008). Revista RA'EGA, Curitiba, v. 21, p. 337-364, 2011.

RONDONÓPOLIS. Prefeitura Municipal. Lei Complementar no 12 de $\mathbf{3 0}$ de dezembro de 2002. Institui o Código Ambiental do Município de Rondonópolis - MT e dá outras providências. Disponível em:

<http://www.rondonopolis.mt.gov.br/docs/Codigo_ambiental.pdf>. Acesso em: 5 out. 2017.

ROSA, R. Introdução ao sensoriamento remoto. 5 ed. Uberlândia: Universidade de Uberlândia, 2003.

SANTOS, G. O.; HERNANDEZ, F. B. T. Uso do solo e monitoramento dos recursos hídricos no córrego do Ipê, Ilha Solteira, SP. Revista Brasileira de Engenharia Agrícola e Ambiental, Campina Grande, v. 17, n. 1, p. 60-68, 2013.

SANTOS, J. B.; PEZZONI FILHO, J. C.; DANTAS, M. J. F.; ZIMBACK, C. R. L.; LESSA, L. G. F. Avaliação da adequação da ocupação do solo em Áreas de Preservação Permanente (APPs). Irriga, Botucatu, v. 19, n. 2, p. 333-344, 2014.

SANTOS, J. W. M. C.; ALVES, G. B. M. Modelagem do potencial de poluição hídrica da bacia hidrográfica do rio Manso - MT. Brazilian Geographical Journal: Geosciences and Humanities Research Medium, Ituiutaba, v. 5, n. 1, p. 289-304, 2014. 
SETTE, D. M.; TARIFA, J. R.; GRIPP, W. G. O ritmo das chuvas e da qualidade das águas do rio Vermelho em Rondonópolis-MT. INTERGEO, Rondonópolis, ano 2, n. 2, p. 92-101, 2002.

SOARES, V. P.; AZEVEDO MOREIRA, A.; ALVARES SOARES RIBEIRO, C. A.; MARINALDO GLERIANI, J. Mapeamento das áreas de preservação permanente e dos fragmentos florestais naturais como subsidio à averbação de reserva legal em imóveis rurais. Cerne, Lavras, v. 17, n. 4, p. 555-561, 2011.

SOUZA, A. V. V. Influência dos usos e ocupação do solo na qualidade da água do rio Vermelho no sudeste de Mato Grosso. 2015. 80 f. Dissertação (Mestrado em Geografia) Universidade Federal de Mato Grosso, Rondonópolis - MT, 2015.

.; LOVERDE-OLIVEIRA, S. M. Analise da qualidade da água do rio Vermelho em Mato Grosso: no período de cheia no ano de 2014. Biodiversidade, Cuiabá, v.13, n. 2, p. 115126, 2014.

SOUZA, M. M.; GASTALDINI, M. C. C. Avaliação da qualidade da água em bacias hidrográficas com diferentes impactos antrópicos. Engenharia Sanitária e Ambiental, Rio de Janeiro, v. 19, n. 3, p. 263-274, 2014.

TONIN, D. Tarifa da água está mais cara em Rondonópolis. A Tribuna Mato Grosso Digital, Rondonópolis-MT, 14 ago. 2013. Disponível em:

<http://www.atribunamt.com.br/2013/08/tarifa-da-agua-esta-mais-cara-em-rondonopolis/>. Acesso em: 18 jun. 2014.

VAEZA, R. F.; OLIVEIRA FILHO, P. C.; MAIA, A. G.; DISPERATI, A. A. Uso e ocupação do solo em bacia hidrográfica urbana a partir de imagens orbitais de alta resolução. Floresta e Ambiente, Rio de Janeiro, v. 17, n. 1, p. 23-29, 2010.

Recebido: junho de 2017. Aceito: outubro de 2017.

\footnotetext{
' Artigo elaborado com base na revisão e atualização de parte dos resultados da Dissertação de Mestrado em Geografia "INFLUÊNCIA DOS USOS E OCUPAÇÃO DO SOLO NA QUALIDADE DA ÁGUA DO RIO VERMELHO NO SUDESTE DE MATO GROSSO", defendida em junho/2015 no Instituto de Geografia da Universidade Federal de Mato Grosso.
} 